\title{
Membaca Indonesia dari Kaca Teori Kompleksitas "Kematian Narasi Besar di Era Kompleksitas Kharakteristik Sosiologis Massa Rakyat"
}

To Read Indonesian by Complexity Theory

"The Death of The Great Narrative In The Complexity Era of Mass Sosiological"

\author{
Alvin Yulityas Sandy \\ Dosen Ilmu Komunikasi, Universitas 17 Agustus 1945 Jakarta \\ Jalan Sunter Permai Raya-Sunter Agung Podomoro Jakarta 14350
}

alvin.sandy@uta45jakarta.ac.id

\begin{abstract}
:
This paper discusses how the dialectical development of the history of Indonesia as a country, as well as Indonesian society in the perspective of Marxism. This paper found that the forecast marxism is not in accordance with the context of Indonesia, in the perspective of information technology will determination, in this paper also directed how should the need for a communication policy is formed.
\end{abstract}

Keywords: Marxisme, Complexity, Policy 


\begin{abstract}
Abstraksi:
Tulisan ini membahas bagaimana perkembangan dialektika sejarah Indonesia sebagai negara, maupun masyarakat indonesia dalam perspektif marxisme, dalam tulisan ini ditemukan bahwa ramalan marxisme tidak sesuai dengan kontek Indonesia, dalam perspektif determinasi teknology informasi, dalam tulisan ini juga diarahkan bagaimana sebaiknya perlunya sebuah kebijakan komunikasi dibentuk.
\end{abstract}

Kata Kunci: Marxisme, Kompleksitas dan Kebijakan. 


\section{PENDAHULUAN}

Indonesia merupakan negara dengan berbagai macam kultur, dan memiliki ribuan pulau yang membentang dari sabang sampai merauke, kondisi geografis yang luas dan membentang menjadikan Indonesia sebagai negara dengan tatanan masyarakat yang unik, sebagian berbentuk industri, sebagian agraris dan sebagian bahkan masih primitif, hal ini diperumit dengan lahirnya era tekhnology informasi, dimana tekhnology ini memiliki determinasi perilaku penggunanya, hal ini akan berpengaruh pada bagaimana sebuah arah kebijakan dilahirkan.

Dalam tulisan ini saya ingin mengajak berdiskusi tentang bagaimana bentuk tatanan masyarakat Indonesia dalam pespektif dialektika sejarah marxisme, yang kemudian mengalami diferensiasi karena lahirnya tekhnology informasi, kelahiran tekhnology informasi menjadi momok tersendiri pada pandangan dialektika sejarah marxisme orthodox, era kekinian bisa dibilang merupakan era kompleksitas, dimana era narasi besar berada pada posisi ujung tanduk.

Di era kompleksitas sistem seperti ini, yang bila merujuk pada dialektika sejarah dan determinasi tekhnologi industri dan kontradiki kelas yang di ramalkan Marx dimana dialektika sejarah peradaban dimulai dari komunal primitif - monarkhi - industri kapitalistik - sosialis - komunal modern, dalam pandangan saya Indonesia memiliki kharakteristiknya sendiri, konteks dialektika 
sejarah di eropa menjadi berbeda karena kondisi geografis, rentang waktu dan perkembangan tekhnology.

Kekacauan dalam membaca kharakteristik sosiologis massa rakyat tentu menjadi tantangan tersendiri bagi pengambil kebijakan dalam menentukan arah kebijakan, mengetahui kharakteristik massa rakyat tentu menjadi suatu keharusan dalam pengambilan kebijakan sebelum menentukan arah pembangunan.

Jurnal ini akan memulai dengan beberapa satu kunci; bagaimana kompleksitas dialektika perkembangan sejarah dalam perspektif marxist di Indonesia?

\section{HASIL ANALISIS}

Karl Marx merupakan salah satu pemikir teori dalam mahzab "deterministik" dimana perilaku aktor atau manusia akan berpengaruh pada materi-materi terkhnology peradaban yang berkembang disekitarnya, bagi Marx materialisme merupakan landasan utama filsafat berpikirnya, dia sangat menentang metode berpikir idelist ala plato, perkembangan materi-materi peradaban bagi Marx akan melahirkan kontradiksi kelas, bagi Marx dialektika sejarah dan kontradiksi kelas, adalah sebuah keniscayaan pemikiran ini dikenal sebagai Marxism orthodox (Ritzer \& Goodman, 2011: 55).

Namun pemikiran Marx ini juga memiliki kelamahan, Marx sama sekali tidak meramalkan sebuah situasi dimana akan lahir era informasi yang mengglobal, dimana perkembangan 
tekhnologi informasi ini juga memiliki determinasi tekhnologi akan kharakteristik sosiologis massa rakyat, yang akan mempengaruhi jalanya dan hasil-hasil budaya suatu peradaban, perkembangan tekhnology melahirkan era kompleksitas peradaban.

Benar terjadi, era pasca perang dunia ke-dua adalah eranya kompleksitas, determinasi perkembangan tekhnology informasi menjadikan ramalan Marx seketika menjadi gugur, namun landasan berpikir materialisme dan deterministiknya masih bisa dijadikan acuan.

Membaca Indonesia pada era kekinian menggunakan dialektika sejarah Marx menjadi sangat rumit, kharakteristik masyarakat Indonesia mengutip pernyataan Max Lane dalam kuliah umum di ruang seminar Pasca Sarjana UGM 22 november 2011 “Indonesia Political History” dia menyatakan bahwa:

"masyarakat indonesia masih dalam tahapan masyarakat pertanian atau agraris monarki, yang memiliki kharakteristik masyarakat yang mistis, dan patronal atau menggantungkan hidupnya pada majikan yang baik" (Lane, 2011).

Kita bisa melihat kesulitan pemerintah dalam menentukan kebijakan, beberapa kebijakan industrialisasi di tolak oleh masyarakat berkultur tani atau agaris, misal rencana pendirian pabrik, rencana pendirian pembangkit listrik, dan rencana penataan pasar tradisional menjadi modern, kebijakan tersebut sering 
mendapatkan penolakan dari masyrakat yang mengkhawatirkan hak-hak ekosobnya terpengaruhi.

Yang unik kemudian ada juga kasus demokratisasi di Yogyakarta, dimana masyarakat Yogyakarta menolak pemilihan langsung pemimpin provinsinya, dalam kasus Yogyakarta ini cukup unik padahal bila melihat sejarah gerakan demokrasi sejak awal berdirinya republik hingga reformasi 98, selalu dipelopori oleh pelajar-pelajar Jogja.

Namun dalam kasus pemimpin kepala daerah justru masyarakat Jogja justru menolak model demokrasi modern yang setara (non paternalstik dan genetik), padahal hal ini tidak sesuai dengan metode demokrasi yang lebih dialektik, kita bisa melihat dalam kasus ini bahwa massa rakyat DIY belum logis dalam bahkan cenderung mistis keratonan.

Kekacauan ini tentu segaris dengan teori-teori posmodernism yang menyatakan matinya naras-narasi besar didunia, matinya ideologi-idelogi besar yang menginginkan sebuah dunia yang tertata berdasarkan strukturaslism dan fungsionalismnya, situasinya menjadi tidak teramalkan, Callinicos mendefinisikan posmodern "sebagai ketidak percayaan pada metanarasi-metanarasi" (Callinicos, 2008:7).

\section{A. Membaca Dialektika Sejarah Indonesia}

Dalam perspektif marxisme, tekhnologi atau alat produksi berpengaruh pada kahrakteristik sosiologis massa rakyat, 
"the mode of production of material life determines the general character of social, political adn spiritual processes of life, it is not consciousness of men that determines their being, but, on contrary, their social being determines their consciousness" (Marx, 1964:51).

Dari penjelasan Marx tersebut dapat diketahui bahwa proses kehidupan sosial mereka menentukan siapa mereka (manusia), yang artinya massa rakyat mengalami determinasi tekhnologi produksi, terpengaruh oleh model-model produksi mereka, namun determinasi ini juga tidak bisa dianggap satu arah, karena antara alat dan manusia juga saling mempengaruhi, dalam perkembanganya manusia melakukan modifikasi terhadap alat produksi, yang mana nantinya alat produksi itu juga mempengaruhi pola kharakteristik sosiologis massa rakyat.

Pada era sekarang, tidak bisa diramalkan pola-pola kharakteristik massa sejarah yang sedang ditempuh, namun penting untuk mengetahui dialektika perkembangan sejarah umat manusia, untuk mengetahui kharakteristik massa rakyat sebagai cara melihat sebuah perkembangan sosiologis "mikro to mikro",

Kompleksitas di Indonesia menjadikan beragamnya massa rakyat, ada beberapa yang sudah mencapai massa informasi, ada yang masih industri bahkan ada yang tertinggal pada massa-massa monarki agraris, dengan mengetahui kharakteristik massa rakyat, berdasarkan pola produksinya, 
maka akan mudah melakukan pemetaan sampai pada tingkatan aktor mikro.

Perkembangan tekhnology saat ini merupakan massa post industri, yang memasuki era informasi, era informasi adalah era dimana pola produksi dan distribusi hasil industri, ditentukan oleh percepatan pepindahan informasi, informasi menjadi kunci dalam distribusi hasil produksi industri, perkambangan tekhnologi juga mempengaruhi, adanya new media, melahirkan network society.

Merujuk pada massa Indonesia saat ini yang sangat luas dan plural, Indonesia memiliki beraneka ragam kharakteristik, bahkan di satu daerah saja bisa memiliki banyak kharakteristik massa rakyat, ada yang agraris ada pula yang informasi, misal massa rakyat yang masih mistis - monarchi agraris (tidak logis dan ilmiah) terkontaminasi oleh tekhnology informasi, yang efeknya kemudian pada penyalahgunaan tekhnology yang menjadi tidak tepat guna.

Pada era Revolusi (1945) setidaknya para founding father kita paham betul tentang arah gerak sejarah bangsa ini, Soekarno melakukan percepatan pada indsutri-industri nasional dengan mendirikan pabrik baja dan melakukan nasionalisasi pada pabrik-pabrik strategis serta pertambangan yang dikuasai oleh belanda.

Sektor agraria juga direspon dengan lincah oleh para pendiri bangsa ini, dengan melakukan reformasi agraria 
dengan membagikan tanah secara merata, kebijakan ini dimaksudkan agar sektor pertanian mengalami surplus yang nantinya surplus ini bisa mendorong pertanian pada pertanian modern dengan sokongan tekhnologi, untuk mengolah hasil pertanian agar terciptanya nilai lebih.

Namun seketika semua berubah sejak era "Kontra Revolusi" (meminjam istilah Max Lane, 2007:38), terjadi kudeta berdarah dengan banyak kontroversi di tahun 1965, tambang-tambang kembali digadaikan, akselarasi modernisasi memang dilakukan tapi tidak terarah, artinya industri-industri strategis tidak diakselarasi tetapi justru menerima barangbarang impor dari luar, atau paling maksimal hanya terjadi produksi di dalam negri tapi modal dari luar negri.

Pada era orde baru yang dipimpin Jendral Soeharto, sektor pertanian mengalami pemaksaan, para petani diwajibkan melakukan menanam beras, hal ini berdampak pada era kini, yaitu minimnya diversitas bentuk pangan yang berdampak pada ketahanan pangan, kebijakan pertanian era orde baru juga tidak diimbangin dengan akselarasi penggunaan tekhnologi pertanian, para petani kita masihlah para petani traditional.

Pada era orde baru semua sektor massa rakyat dikuasai melalui sistem komando teritorial militer, bahkan sampai tingkatan RT yang dikenal dengan Babinsa, merujuk pada teori strukturasi era orde baru sangat Parsonian, dimana siri khas Struktur Fungsional parson memiliki "persyaratan kunci bagi 
PROMEDIA, VOLUME I, NO 1, 2015, Sandy, Membaca Indonesia, 1-18

terpeliharanya integrasi pola nilai didalam sistem adalah melalui proses internalisasi dan sosialisasi" (Goodman \& Ritzer, 2011: 125).

Pada era itu orde baru sangat gencar melakukan internalisasi melalui propaganda-propaganda baik melalui film, lagu maupun penataran P4 di kampus-kampus, konflik menuju perubahan menjadi sangat haram pada era itu, banyak agen-agen (aktor) perubahan diculik dan dihilangkan demi kestabilan sistem.

Tahun 98 terjadi gerakan massa rakyat menentang tirani orde baru yang dipimpin oleh mahasiswa, agen / aktor berhasil melakukan perubahan denganstrategi-strategi bawah tanahnya, melakukan perlawanan yang awalnya tidak terbuka, namun menjadi terbuka setelah sistem goyah karena dihantam krisis ekonomi dunia, situasi krisis sembako ditambah dengan kenaikan harga barang-barang lainnya, mendorong krisis sistemik terjadi.

Reformasi 98 juga terjadi karena dukungan proses informasi yang mudah terjadi setelah masuknya internet di Indonesia di tahun 1996, perlawanan dan pengorganisiran dilakukan melalui milist-milist yang tidak terkontrol oleh rezim saat itu, rezim saat itu belum bisa membentuk sistem mengikuti perubahan tekhnologi informasi, pada tahapan ini ktia bisa melihat lagi bagaimana determinasi tekhnology dapat berpengaruh pada perkembangan dialektika sejarah. 
Sampai saat ini masih belum jelas blue print arah perkembangan bangsa Indonesia, massa agraria yang belum benar-benar rampung, namun di beberapa tempat sudah berhasil membentuk massa industri, bahkan ada juga massa informasi, berkembangnya tekhnology informasi terutama internet membuat semakin berkembangnya wacana akan dunia, kita seperti teritegrasi secara utuh dalam desa dunia.

\section{B. Membaca Kompleksitas Aktor (rakyat) di Indonesia}

Demokratisasi seperti menjadi keharusan, namun pola politiknya masih pola politik patornal agraris, misal ketokohan Hamengku Buwono di DIY, menjadi contoh nyata bahwa massa rakyat Indonesia masih berkharakteristik Agraris traditional, penokohan Gusdur dan Megawati, serta tokoh lainnya yang memiliki keturunan darah orang besar dimasa lalu, dan juga dalam pilkada-pilkada daerah tak jarang membawa nama-nama pemimpin agama setempat, atau bahkan darah keturunan.

Hal tersebut sebetulnya menunjukan bagaimana Yogyakarta dengan budaya pendidikannya, bisa menjadi kota yang lebih mengedepankan logika ilmiah ketimbang logika keturunan (sultan), namun pola politik patronal khas negara agraris masih dipilih oleh sebagian besar masyarakat jogja, di Jogjakarta ada paradox yang unik, begitu pula dengan penokohan-penokohan aktor yang memiliki keturunan darah 
tokoh besar di masa lalu juga terjadi, hal ini menunjukan bagaimana sebagian masyarkat Indonesia masih berkharaktersitikan agraris monarki.

\section{Dampak Perkembangan Tekhnology Informasi}

Perkembangan tekhnologi informasi tak bisa dibendung, Indonesia menjadi pangsa pasar potensial, internet, komputer, televisi, mobile phone, terus berkembang, dijual dalam jumlah besar dan murah, kekacauan kharakteristik massa rakyat yang akibat dari pembangunan bangsa yang tidak mengarah pada kharakter building, ditambah lagi perubahan kharakteristik akibat tekhnologi informasi, hal ini menjadikan situasi Indonesia sangat kompleks.

Arus informasi yang bebas dari media massa, ditambah new media yang melahirkan percepatan informasi, yang bisa diakses oleh multi peradaban dialektika sejarah, dalam berbagai kharakteristik sosiologis itu, menghasilkan massa rakyat yang imitatif terhadap trend yang terjadi diberbagai belahan dunia.

Trend politk, trend fashion, trend gaya hidup, trend perlawanan, situasinya menjadi sangat kompleks, perlawanan Sondang Hutagalung misal, yang membakar diri didepan istana, dia meniru aksi yang dilakukan di Suriah, padhal situasi sejarah dan konteks yang terjadi berbeda antara Indonesia dan 
Suriah, trend pernikahan Royal Weeding Inggris, di DIY juga ditiru dengan pernikahan putri keraton.

Kenapa hal itu terjadi, penulis melihat ada beberapa masalah, pertama persoalan belum rampungnya Indonesia melalui massa agrarisnya, dengan kharakteristik masssa rakyat yang mistis kita dapat melihat kurang efektifnya media massa, media massa berisi tayangan-tayangan mistis dan imitatif.

Situasi seperti ini semakin diperumit dengan masuknya new media dan tekhnologi informasi, mereka menerima informasi tanpa adanya literasi dan pola pikir yang logis non mistis, keberadaan new media hanya menambah ke "kaguman", tanpa bisa memahami esensi dan landasan filosofisnya, terkadang mereka meniru tanpa mengetahui teks dan konteks yang terjadi di balik semua informasi yang mereka terima.

Kedua massa rakyat penghuni kota yang belum benarbenar terbentuk budaya pekerja industri, mengutip pernyataan Max Lane bahwa menurut dia "Indonesia belum benar-benar memiliki industri besar, yang bisa membentuk kharakteristik massa rakyat yang logis dan non patron-klien", industri kecil yang hanya usaha manufaktur, atau sekedar pengolahan bahan mentah menjadi setengah jadi bukanlah industri yang bisa mengakumulasikan kapital, berkembangnya kapitalisme besar menurut Lane merupakan salah satu syarat terbentuknya sistem masyarakat yang logis dan mengedepankan kesetaraan. 


\section{Kebijakan Komunikasi Deliberatif Untuk Mendorong Perubahan}

Dari penjabaran tersebut dapat ditemukan bahwa massa rakyat Indonesia, dalam dialektika Marxisme Indonesia mash pada awal pra perang dunia kedua, dengan bentuk corak agraris, menuju transisi industrialisasi, tapi situasi terebut tidak bisa diperlakukan pula dalam konteks sosial pra perang dunia kedua atau pra industrialisasi di Eropa, dengan cara-cara mobilisasai rakyat secara paksa/ otoriter.

Pada masa itu kompleksitas arus informasi dan globalisasi belum sekompleks saat ini, selain itu belum ada pula piagampiagam dunia yang melindungi hak asasi manusia, jadi tidak mungkin pula melakukan represi paksa untuk melakukan pecepatan pembangunan industrialisasi seperti yang terjadi pada revolusi industri di Perancis dan Inggris pasa massa itu

Pembangunan tidak bisa lagi menggunakan cara-cara rezim otoriter untuk mendorong pada perubahan, beberapa negara berhasil menerapkan rezim otoriter dan memang negara itu berhasil maju dan kharakter buildingnya terbentuk, namun hal itu terjadi pada massa ketika tekhnologi informasi belum maju, dan efek determinasi kompleksitas informasi belum terasa, semua masih tercentral dan aktornya masih sedikit.

Berbicara soal komunikasi sebagai elemen dasar masyarakat (mengutip Luhman dalam Goodman \& Ritzer, 
2011: 243) , untuk membentuk sistem yang disadari secara penuh oleh aktor-aktor didalamnya maka diperlukan diciptakan sebuah ruang yang lepas dari segala intervensi, baik fisik, psikis, kepentingan pasar, negara bahkan publik itu sendiri, peran aktif aktor menjadi sangat penting untuk menciptakan sebuah sistem yang efektif.

Mengutip Habermas situasi yang diandaikan diatas merupakan situasi "ruang publik", menurut Habermas ruang publik adalah:

"a domain of our social life where such a thing as public opinion can be formed (where) citizen .. deal with matters of general interest wihtout being subject to coercion...(to) express and publicize their views" (dalam McKee, 2005:4).

Dapat diartika sebuah situasi dimana publik dapat mendiskkusikan masalah bersama mereka tanpa mereka menjadi subjek paksaan.

Artinya dalam menciptakan sebuah sistem regulasi arah pembangunan dalam situasi kompleksitas saat ini, tidak bisa lagi negara menerapkan up to bottom, namun tetap harus melihat dari bawah keatas, keterlibatan aktif masyarakat dalam melihat dan memahami arah regulasi akan membawa mereka pada partisipasi aktif dalam sebuah sistem, mereka tidak lagi dipaksa, namun diajak untuk bersama-sama membaca situasi dan kebutuhan mereka, komunikasi menjadi kata kuncinya. 
Untuk menggerakan sebuah sistem yang sudah tertata matang diperlukan stimulus dari luar, diperlukan penyebab sebuah tindakan, Luhman menyebutnya sebagai sistem psikis "apa-apa yang tidak bermakna dilihat berada diluar sistem, sebagai penyebab tindakan kita" (dalam Goodman \& Ritzer, 2011: 248),

Misalkan dalam tatanan masyarakat petani yang akan di dorong menjadi masyarakat industri tidak bisa didorong dengan tindakan paksaan, namun dengan menciptakan kondisi syarat dan prasyarat agar masyarakat petani dapat keluar dari sistem pertanian traditional.

\section{REKOMENDASI}

Dalam melakukan pembacaan sebuah sistem, karena semakin banyaknya peran aktor dalam sebuah sistem, baik itu sistem secara mikro maupun sistem secara makro (dimana sistem kecil sebagai aktor), dapat ditarik kesimpulan bahwa saat ini sangat sulit untuk melakukan prediksi dan arahan, bisa dibilang era ini adalah era chaos.

Berangkat dari pemahaman sudah kacaunya kharakteristik sosiologis yang tidak hanya bisa dibaca berdasarkan kharakteristik pola produksinya (akibat dari determinasi tekhnologi informasi), pembacaan di Indonesia, hanya bisa dilakukan dengan bottom up, pembacaan fenomena sosial dari kondisi-kondisi lingkungan 
terkecil (micro to micro), yang kemudian dirangkaikan berdasarkan kharakteristiknya.

Dalam satu lingkungan geografis saja belum tentu memiliki satu kharakteristik, misalkan Jogjakarta, dalam lingkup kecil ini saja terdiri dari berbagai macam kharakteristik, kharakteristik akademis, agraris, kharatersitik informatif, namun dalam kondisi tersebut bukan berarti bahwa situasi yang kacau tersebut tidak memiliki polanya tersendiri.

Luhman berpendapat salah satu syarat terbentuknya sebuah sistem adalah adanya situasi chaos, artinya kita tidak perlu pesimis dengan situasi sekarang ini, saat ini sedang terjadi proses evolusioner budaya masyarakat, yang perlu dipersiapkan adalah dengan mempertahan situasi diskursus yang bisa diakses oleh semua massa rakyat, kebijakan-kebijakan tidak lagi bisa merupakan kebijakan tersentral, regulator harus bisa menyiapkan dan menyediakan ruang proses diskursus bottom up.

Hampir mustahil melakukan pembacaan "narasi besar" pada situasi seperti ini, tidak ada lagi narasi besar yang mampu dipertahankan, situasi akhir 1800an hinggan ahir 1900an sudah sangat berubah, perkambangan tekhnology informasi membuat manusia hidup tidak terbataskan ruang dan waktu, mereka hidup dalam lingkup desa dunia, mereka hidup dengan jaringan networking yang luas, pembacaan fenomena sosial hanya bisa dilakukan sepotong-sepotong, seperti menyatukan potonganpotongan puzle. 


\section{Daftar Pusataka}

Callinicos, Alex, 2008, "Menolak Posmodernisme". Yogyakarta: Resist Book.

Foss AK \& Littlejohn SW, 2009, "Encyclopedia of Communication Theory". India: Sage Publication.

Giddens, Anthony, 1989, "A Reply to My Critics", in D.Held and J.B Thompson (eds.), Social Theory of Modern Societties: Anthony Giddens and His Critics. Cmabridge, Eng: Cambridge University Press.

Goodman DJ \& Ritzer G, 2011, "Teori Sosiologi Modern". Jakarta: Kencana.

Lane, Max, 2007, “Bangsa Yang Belum Selesai”. Jakarta: Reform Istitute.

Loon VB \& Sim S, 2008, “Memahami Teori Kritis”. Yogyakarta: Resist Book.

Marx, Karl, 1964. "Selecter writings in sociology and social philosophy" (T.B.Bottomore\&M.Rubwel,eds). New York: McGrawhill.

Mckee, Alan, 2005, “The Public Sphere: An Introduction”. UK: Cambride University.

Touraine, Alain, 1977, The Self-Production of Society. Chicago: University of Chicago Press. 